\title{
A Comparative Study to Assess the Advantages of Preservation of Posterior Ligamentous Complex in Decompressive Surgeries for Lumbar Spinal Canal Stenosis
}

\author{
Suresh Sivadasan Pillai ${ }^{1}$, Asif Hassan K. ${ }^{2}$ \\ ${ }^{1}$ Department of Orthopaedics, Travancore Medicity Medical College Hospital, Kollam, Kerala, India. \\ ${ }^{2}$ Department of Orthopedics, Aster Mims Hospital Calicut, Kerala, India.
}

\section{ABSTRACT}

\section{BACKGROUND}

In this study we wanted to test hypothesis that posterior ligament complex preserving decompression has advantages over conventional decompression surgeries for the treatment of lumbar canal stenosis, assess clinical and functional outcome following decompression surgeries whether preservation has advantages over routine decompression and use radiological parameters pre operatively and post operatively to evaluate whether there is adjacent segment degeneration following decompression surgeries for canal stenosis.

\section{METHODS}

This is a prospective study conducted among in-patient and outpatient follow ups of the Department of Orthopaedics of MIMS Hospital, Calicut, over a period of 22 months from February 2017 to November 2018.

\section{RESULTS}

The mean age of patients included in the study in PLC preserved group was $58.68 \pm$ 11.3 years and in PLC non-preserved group, it was $62.75 \pm 11.18$ years. There was a slight female predominance in PLC preserved group (60\%) and in PLC non preserved group male to female ratio was 1:1 At 1 year follow up both the groups of patients had significant relief of symptoms and had improved functional outcome. At 1 year follow up ODI and VAS score were better in PLC preserved group compared with PLC not preserved group. There was adjacent segment disc height improvement in both the groups, and was maintained in the PLC preserved group while during the final follow up there was slight reduction in the mean disc height in PLC not preserved group. Intervertebral disc angle and total lumbar lordosis in both the groups were comparable during 1 year follow up. Adjacent segment slip was not noted in both the groups. Adjacent segment degeneration was not detected in both the groups.

\section{CONCLUSIONS}

Lumbar decompressive surgeries with both PLC preserving and non-preserving surgeries can provide significant relief of symptoms to the patient. PLC preserving surgeries provide better functional outcome during the 1 year follow up period. Similarly residual pain was also less in the PLC preserved group. Adjacent segment degeneration was not detected in both the groups during the one year follow up.

\section{KEY WORDS}

Posterior Ligamentous Complex, Decompressive Surgeries, Lumbar Spinal Canal Stenosis
Corresponding Author: Dr. Suresh Sivadasan Pillai, Senior Consultant Spine Surgeon, Department of Orthopaedics, Travancore Medicity Medical College Hospital, Kollam, Kerala, India. E-mail: sureshorth@gmail.com

DOI: $10.14260 /$ jemds/2022/49

How to Cite This Article: Pillai SS, Hassan KA. A Comparative study to assess the advantages of preservation of posterior ligamentous complex in decompressive surgeries for lumbar spinal canal stenosis. J Evolution Med Dent Sci 2022;11(01):259-264, 10.14260/jemds/2022/49

Submission 16-12-2021, Peer Review 23-12-2021, Acceptance 29-01-2022, Published 31-01-2022.

Copyright (c) 2022 Suresh Sivadasan Pillai et al. This is an open access article distributed under Creative Commons Attribution License [Attribution 4.0 International (CC BY 4.0)] 


\section{BACKGROUND}

As we age, the spine changes, often leading to a degeneration of the vertebrae (bones), discs, muscles and ligaments (connective tissues) that together make up the spinal column. ${ }^{1}$ This condition is particularly common in aged or those with degenerative spine disease. ${ }^{2}$ Spinal stenosis is a narrowing of the spinal canal or neural foramina producing root ischemia and neurogenic claudication. ${ }^{3}$ The causes for spinal canal stenosis are:

\section{Bony Structures}

- Facet osteophytes

- Uncinate spur

- Spondylolisthesis

- Soft tissue structures :

- Herniated or bulging discs

- Hypertrophy or buckling of the ligamentum flavum

- Synovial facet cysts

Degenerative changes that are part of aging process may lead to compression of neurologic tissues within the spinal canal. This compression occurs slowly and gradually affects the blood supply (arterial inflow and venous outflow. ${ }^{3}$ The typical symptoms of lumbar spinal canal stenosis include low back pain, sciatica, numbness and intermittent claudication, ${ }^{4}$ all of which may lead to functional deficits. ${ }^{5}$ Treatment options for lumbar canal stenosis may be surgical or nonsurgical. 6

Non-surgical treatments, such as physical and pharmacological therapy were reported to be effective for promoting symptom relief in $15-43 \%$ of patients. ${ }^{7}$ However surgery is indicated in patients who do not respond to conservative treatment. ${ }^{8}$ Indeed, most patients with extensive lumbar canal stenosis undergo surgery to alleviate symptoms and improve function. ${ }^{9}$

\section{Objectives}

1. To test hypothesis that Posterior ligament complex preserving decompression has advantages over conventional decompression surgeries for the treatment of lumbar canal stenosis

2. To assess clinical and functional outcome following decompression surgeries whether preservation has advantages over routine decompression.

3. To use radiological parameters pre operatively and post operatively to evaluate whether there is adjacent segment degeneration following decompression surgeries for canal stenosis.

\section{METHODS}

This is a prospective study conducted among in-patient and outpatient follow ups of the Department of Orthopaedics of MIMS Hospital, Calicut, over a period of 22 months from February 2017 to November 2018.

\section{Inclusion Criteria}

1) Disabling back pain or leg pain with or without neurological symptoms with lumbar canal stenosis confirmed on MRI scan

2) Radiological and clinical follow up of 1 year

\section{Exclusion Criteria}

1) Congenital bony lesions of the spine

2) Acute spinal fracture

3) Infection

4) Mass lesion in the spine

5) History of rheumatologic diseases

\section{Sample Size}

Total of 80 patients, 40 patients underwent PLC preserving laminectomy, decompression, instrumentation and posterolateral fusion while the other 40 underwent the same procedure without preserving PLC. Sample size is calculated using the equation $n=2 \sigma 2 *(\mathrm{Z} \alpha+Z \beta) 2 \delta 2$

We fix $\alpha$ as 0.05 (5\%) $\beta$ as $0.20(20 \%)$ so that power (1- $\beta$ ) is $80 \%$.

Previous study (outcome after surgery of lumbar spinal stenosis: A randomized comparison of bilateral laminotomy, trumpet laminectomy and conventional laminectomy)) shows the average ODI score in the conventional laminectomy treatment group was 28 with a SD of 12 . No previous data available on PLC preserving laminectomy.

For detecting a reduction of 3 score in ODI in the PLC preserving laminectomy, the sample size required is 30 . Considering a lost to follow up of $20 \%$ a sample of 36 is required per group. So we will include sample of 40 / group.

\section{Method of Measurement of Outcome of Interest}

Patients are randomly allotted in to two groups using MS EXCEL between $(1,2)$, group 1 undergoing PLC preserving decompressive surgeries and group 2 undergoing decompressive surgeries without retaining PLC,for lumbar canal stenosis. This method of randomization could not be followed strictly as in some cases intraoperative decisions were taken to remove the supraspinous ligament due to its poor quality or there was accidental rupture of ligament.

\section{Statistical Methods}

VAS score, ODI score were considered as primary outcome variables. Disk height, IV disk angle, total lumbar lordosis parameters were considered as secondary outcome variables. Surgical Approach group (PLC preserved Vs PLC not preserved) was considered as Primary explanatory variable. Age, gender were considered as study relevant variables.

Descriptive analysis was carried out by mean and standard deviation for quantitative variables, frequency and proportion for categorical variables. Non-normally distributed quantitative variables were summarized by median and interquartile range (IQR). Data was also represented using appropriate diagrams like bar diagram, pie diagram and box plots. 
All Quantitative variables were checked for normal distribution within each category of explanatory variable by using visual inspection of histograms and normality Q-Q plots. Shapiro- wilk test was also conducted to assess normal distribution. Shapiro wilk test $p$ value of $>0.05$ was onsidered as normal distribution.

For normally distributed age, disk height parameter the mean values were compared between study groups using Independent sample t-test (2 groups). For nonnormally distributed ODI, VAS, IV disk angle, total lumbar lordosis different time periods parameters, Medians and Interquartile range (IQR) were compared between study groups using Mann Whitney u test (2 groups).Categorical outcomes were compared between study groups using Chi square test. $\mathrm{P}$ value $<0.05$ was considered statistically significant. IBM SPSS version 22 was used for statistical analysis. ${ }^{1}$

\section{RESULTS}

A total of 80 subjects were included in the final analysis. Among the study population, 40 (50\%) participants were PLC preserved group and 40 (50\%) participants were PLC nonpreserved group.

The mean age of subjects in PLC preserved group was $58.68 \pm 11.3$ years and in PLC Non-preserved group, it was $62.75 \pm 11.18$ years. The difference in the age between the two groups was statistically not significant (P Value 0.109). In PLC preserved group $24(60 \%)$ were female and remaining 16 (40\%) were male. In PLC non-preserved group 20 (50\%) were female and remaining $20(50 \%)$ were male. The difference in the proportion of surgical approach between gender was statistically not significant (P value 0.369 ).

There was no statistically significant difference between two groups in ODI preoperative, post-operative follow up (P> 0.05). Among the people with PLC preserved group, the median ODI at $6^{\text {th }}$ week follow up was $14($ IQR 12,18$)$ and it was 17 (IQR 12, 24) in people with PLC not preserved group. The difference in the ODI $6^{\text {th }}$ week follow up between surgical approach was statistically significant (P Value $<0.05$ ). Among the people with PLC preserved group, the median ODI at $3^{\text {rd }}$ month follow up was 10 (IQR 8, 12) and it was 11 (IQR 8, 21.5 ) in people with PLC not preserved group. The difference in the ODI $3^{\text {rd }}$ month follow up between surgical approach was statistically significant ( $P$ Value $<0.05$ ). Among the people with PLC preserved group, the median ODI at $6^{\text {th }}$ month follow up was 8 (IQR 5, 10) and it was 8 (IQR 6, 19.5) in people with PLC not preserved group. The difference in the ODI $6^{\text {th }}$ month follow up between surgical approach was statistically significant ( $\mathrm{P}$ Value $<0.05$ ). Among the people with PLC preserved group, the median ODI at $1^{\text {st }}$ year follow up was 4.5 (IQR 4, 7.5) and it was 7.5 (IQR 4, 18) in people with PLC not preserved group. The difference in the ODI $1^{\text {st }}$ year follow up between surgical approach was statistically significant (P Value $<0.05$ ).

There was no statistically significant difference between two groups in VAS score pre-operative, post-operative follow up $(\mathrm{P}>0.05)$. Among the people with PLC preserved group, the median VAS score at $6^{\text {th }}$ week follow up was 3 (IQR 2, 3.75) and it was 3.5 (IQR 3, 5) in people with PLC not preserved group. The difference in the VAS score $6^{\text {th }}$ week follow up between surgical approach was statistically significant (P Value <0.05). Among the people with PLC preserved group, the median VAS score at $3^{\text {rd }}$ month follow up was 2 (IQR 2, 2) and it was 3 (IQR 2, 5) in people with PLC not preserved group. The difference in the VAS score $3^{\text {rd }}$ month follow up between surgical approach was statistically significant ( $P$ Value $<0.05$ ). Among the people with PLC preserved group, the median VAS score at $6^{\text {th }}$ month follow up was 1 (IQR 1, 2) and it was 2 (IQR 1, 5) in people with PLC not preserved group. The difference in the VAS score $6^{\text {th }}$ month follow up between surgical approach was statistically significant (P Value <0.05). Among the people with PLC preserved group, the median VAS score at $1^{\text {st }}$ year follow up was 1 (IQR 1,1$)$ and it was 1 (IQR 1, 1.475) in people with PLC not preserved group. The difference in the VAS score $1^{\text {st }}$ year follow up between surgical approach was statistically significant (P Value $<0.05$ ).
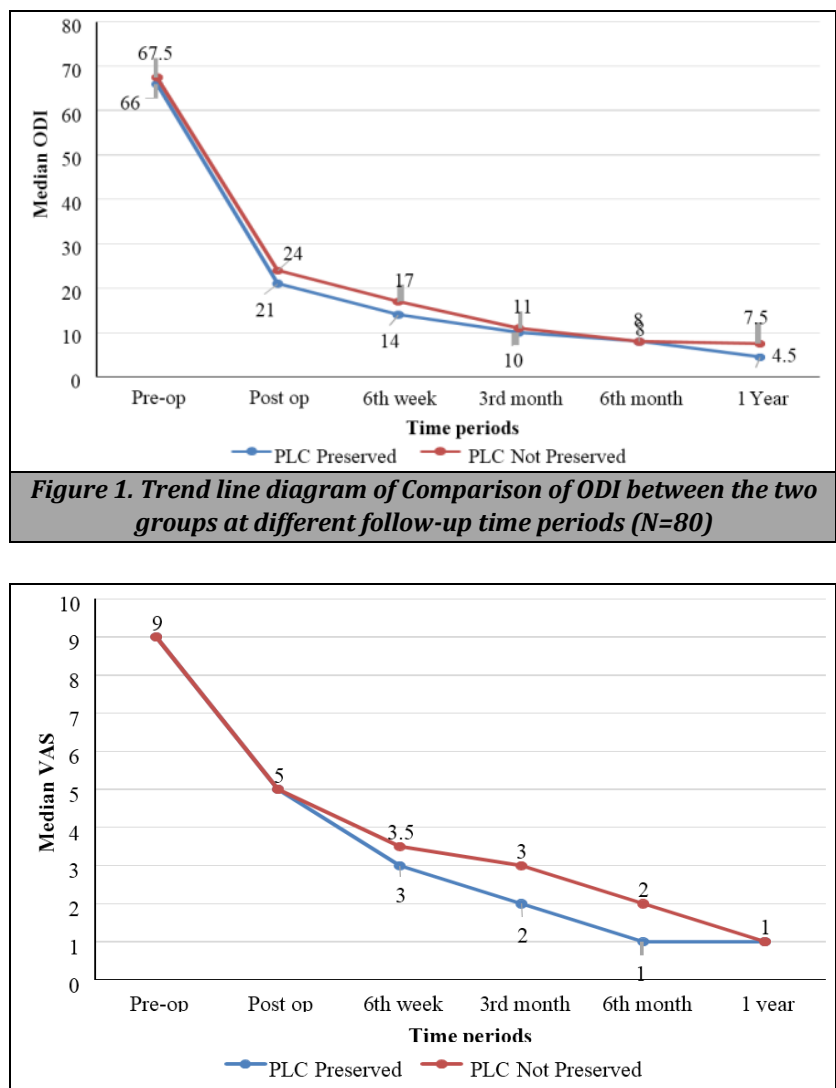

Figure 2. Trend line diagram of comparison of VAS between the two groups at different follow-up time periods $(N=80)$

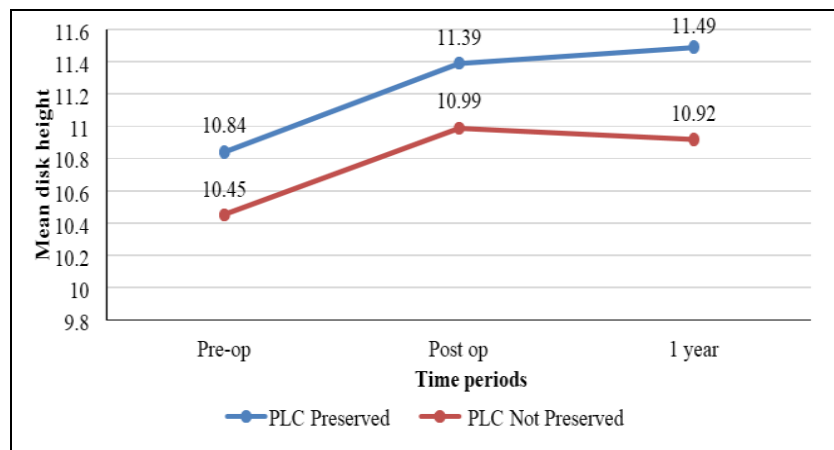

Figure 3. Trend line diagram of Comparison of Disc Height between the two groups at different follow-up time periods $(N=80)$ 
In the PLC preserved group the mean disc height was $10.84 \pm$ 1.59 , immediate post op was $11.39 \pm 1.51$ and at 1 year follow up was $11.49 \pm 1.53$.In the PLC not preserved group the mean disc height was $10.45 \pm 1.82$, immediate post op was $10.99 \pm$ 1.8 and at 1 year follow up was $10.92 \pm 1.76$ There was no statistically significant difference between two groups in disk height pre-operative, post-operative and 1 year follow up (P> 0.05).

In the PLC preserved group the median IV disc angle of the adjacent segment was $6(5,7)$ in the pre op, $7(6,8)$ in the immediate post op and $7(6,8)$ at 1 year follow up. In the PLC not preserved group the median IV disc angle was $6(5,7)$ at pre op, $7(6,7)$ at immediate post op and $7(6,8)$.There was no statistically significant difference between two groups in IV-disk angle pre-operative, post-operative and 1 year follow up $(\mathrm{P}>0.05)$.

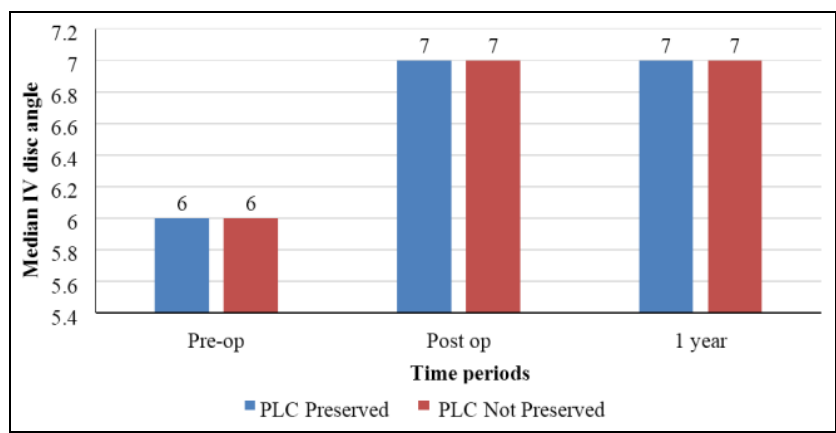

Figure 4. Clustered bar chart of comparison of IV-disc angle between the two groups at different follow-up time periods $(N=80)$

There was no statistically significant difference between two groups in total lumbar lordosis pre-operative, postoperative and 1 year follow up $(\mathrm{P}>0.05)$.

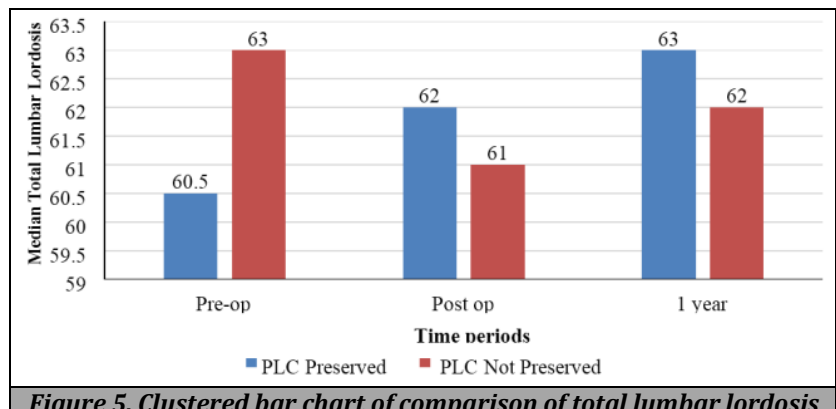

Figure 5. Clustered bar chart of comparison of total lumbar lordosis between the two groups at different follow-up time periods $(N=80)$

\begin{tabular}{|cccc|}
\hline & Parameter & $\begin{array}{c}\text { ODI Median } \\
\text { (IQR) }\end{array}$ & $\begin{array}{c}\text { P value (Wilcoxon } \\
\text { signed Test) } \\
\text { (Base line) }\end{array}$ \\
\cline { 2 - 4 } & Pre-op & $66(62,70.75)$ & $<0.001$ \\
PLC Preserved & Post op & $21(17,24)$ & $<0.001$ \\
group & 3th $^{\text {th }}$ moek & $14(12,18)$ & $<0.001$ \\
& 6th month & $10(8,12)$ & $<0.001$ \\
& 1 year & $6(4,8)$ & $<0.001$ \\
& Pre-op & $67.5(64,7)$ & (Base line) \\
& Post op & $24(18,26)$ & $<0.001$ \\
PLC Non- & $6^{\text {th }}$ week & $17(12,24)$ & $<0.001$ \\
preserved group & $3^{\text {rd } \text { month }}$ & $10(8,22)$ & $<0.001$ \\
& 6th month & $8(6,20)$ & $<0.001$ \\
& 1 year & $6(4,18)$ & $<0.001$ \\
\hline Table 1. Comparison of median values of ODI within the group at \\
different follow up periods (N=80)
\end{tabular}

In PLC preserved group, the median ODI score was 66 (62, $70.75)$ at preoperative, $21(17,24)$ at post-operative, $14(12$, $18)$ at $6^{\text {th }}$ week follow up, $10(8,12)$ at $3^{\text {rd }}$ month follow up, 6 $(4,8)$ at $6^{\text {th }}$ month follow up and $5(4,7.5) 1^{\text {st }}$ year follow up.
The differences in the ODI score at post-operative, $6^{\text {th }}$ week, $3^{\text {rd }}$ month $6^{\text {th }}$ months and $1^{\text {st }}$ year follow up period with baseline value (pre-operative) were statistically significant (P value $<0.001$ ). In PLC not preserved group, the median ODI score was $67.5(64,74)$ at pre-operative, $24(18,26)$ at postoperative, $17(12,24)$ at $6^{\text {th }}$ week follow up, $10(8,22)$ at $3^{\text {rd }}$ month follow up, $8(6,20)$ at $6^{\text {th }}$ month follow up and $6(4,18)$ at $1^{\text {st }}$ year follow up. The differences in the ODI score at postoperative, $6^{\text {th }}$ week, $3^{\text {rd }}$ month $6^{\text {th }}$ months and $1^{\text {st }}$ year follow up period with baseline value (pre-operative) were statistically significant ( $\mathrm{P}$ value $<0.001$ ).

\begin{tabular}{|c|c|c|c|}
\hline & Parameter & $\begin{array}{l}\text { VAS Median } \\
\text { (IQR) }\end{array}$ & $\begin{array}{c}\text { P value (Wilcoxon } \\
\text { signed Test) }\end{array}$ \\
\hline \multirow{6}{*}{$\begin{array}{l}\text { PLC Preserved } \\
\text { group }\end{array}$} & Pre-op & $9(8,9)$ & (Base line) \\
\hline & Post op & $5(4,6)$ & $<0.001$ \\
\hline & $6^{\text {th }}$ week & $3(2,3.75)$ & $<0.001$ \\
\hline & $3^{\text {rd }}$ month & $2(2,2)$ & $<0.001$ \\
\hline & 6th month & $1(1,2)$ & $<0.001$ \\
\hline & 1 year & $1(1,1)$ & $<0.001$ \\
\hline \multirow{6}{*}{$\begin{array}{l}\text { PLC Non- } \\
\text { preserved group }\end{array}$} & Pre-op & $9(8.25,9)$ & (Base line) \\
\hline & Post op & $5(4,6)$ & $<0.001$ \\
\hline & $6^{\text {th }}$ week & $3.5(3,5)$ & $<0.001$ \\
\hline & $3^{\text {rd }}$ month & $3(2,5)$ & $<0.001$ \\
\hline & 6th month & $2(1,5)$ & $<0.001$ \\
\hline & 1 year & $1(1,4.75)$ & $<0.001$ \\
\hline
\end{tabular}

In PLC preserved group, the median VAS score was $9(8,9)$ at pre-operative, $5(4,6)$ at post-operative, $3(2,3.75)$ at $6^{\text {th }}$ week follow up, $2(2,2)$ at $3^{\text {rd }}$ month follow up, $1(1,2)$ at $6^{\text {th }}$ month follow up and $1(1,1) 1^{\text {st }}$ year follow up. The differences in the VAS score at post-operative, $6^{\text {th }}$ week, $3^{\text {rd }}$ month $6^{\text {th }}$ months and $1^{\text {st }}$ year follow up period with baseline value (pre-operative) were statistically significant ( $P$ value $<0.001)$. In PLC not preserved group, the median VAS score was $9(8.25,9)$ at pre-operative, $5(4,6)$ at post-operative, 3.5 $(3,5)$ at $6^{\text {th }}$ week follow up, $3(2,5)$ at $3^{\text {rd }}$ month follow up, $2(1,5)$ at $6^{\text {th }}$ month follow up and $1(1,4.75)$ at $1^{\text {st }}$ year follow up. The differences in the VAS score at post-operative, $6^{\text {th }}$ week, $3^{\text {rd }}$ month $6^{\text {th }}$ months and $1^{\text {st }}$ year follow up period with baseline value (pre-operative) were statistically significant ( $\mathrm{P}$ value $<0.001$ ).

\section{DISCUSSION}

\section{ODI Score}

In both PLC retained and not, comparing with the base line values there was significant change in the ODI scores post operatively, i.e. there was much symptom relief and improved functionality in both the groups. In PLC preserved group the median ODI score was $66(62,70.75)$ at pre-operative, $21(17$, $24)$ at post-operative, $14(12,18)$ at 6 th week follow up, 10 $(8,12)$ at 3 rd month follow up, $6(4,8)$ at 6 th month follow up and $5(4,7.5) 1$ st year follow up. In PLC not preserved group median ODI score was $67.5(64,74)$ at pre-operative, $24(18$, $26)$ at post-operative, $17(12,24)$ at 6 th week follow up, 10 $(8,22)$ at 3 rd month follow up, $8(6,20)$ at 6 th month follow up and $6(4,18)$ at 1 st year follow up. In a study by Haichun Liu to assess the outcomes following various surgical decompression techniques for spine, the clinical and functional outcome where assessed using JOA score. All the patients had satisfactory improvement/ alleviation of symptoms irrespective of the technique of surgery. ${ }^{10}$ 
Comparing between the groups the ODI score in PLC preserved groups were better compared to the PLC not preserved group, stating that PLC preserved decompression surgeries have better functional outcome during the 1 year follow up period. In the study by Haichun Liu et al comparing the different surgical decompression techniques with a follow up period of 5-7 years the initial functional outcomes were comparable in the three groups, but on long term follow ups outcomes of complete laminectomy group were poorer compared to the group which underwent facet joint resection using undercutting decompression preserving PLC. ${ }^{10}$

\section{VAS Score}

In both the groups comparing with the preoperative values there was significant reduction in VAS score. In the PLC preserved group the median VAS score was $9(8,9)$ at preoperative, $5(4,6)$ at post-operative, $3(2,3.75)$ at 6 th week follow up, $2(2,2)$ at 3rd month follow up, $1(1,2)$ at 6 th month follow up and $1(1,1)$ 1st year follow up. In PLC not preserved group, the median VAS score was $9(8.25,9)$ at preoperative, $5(4,6)$ at post-operative, $3.5(3,5)$ at 6 th week follow up, $3(2,5)$ at 3rd month follow up, $2(1,5)$ at 6th month follow up and $1(1,4.75)$ at 1 st year follow up. In a study done by Hadadi et al comparing the outcome of three different surgeries(bilateral laminotomy, trumpet laminectomy and conventional laminectomy),all the three groups had significant reduction in VAS score compared to the pre op values and there is increase in walking distance post op. ${ }^{1}$

Comparing between the groups the VAS score in PLC preserved groups were better compared to the PLC not preserved group, stating that PLC preserved decompression surgeries have better pain relief during the 1 year follow up period. Also there was no statistically significant difference between two groups in VAS score preoperative and immediate post-operative follow up.

\section{Disc Height}

The disc height evaluation was done to assess mainly the adjacent segment degeneration. Most of the previous reports have principally described the cranial segment degeneration after fusion. The assessment was done only on the cranial segment. In the PLC preserved group the mean disc height was $10.84 \pm 1.59$, immediate post op was $11.39 \pm 1.51$ and at 1 year follow up was $11.49 \pm 1.53$. In the PLC not preserved group the mean disc height was $10.45 \pm 1.82$, immediate post op was $10.99 \pm 1.8$ and at 1 year follow up was $10.92 \pm 1.76$. There was no statistically significant difference between two groups in disc height pre-operative, post-operative and 1 year follow up. The evaluation reveals that there was improvement in the adjacent segment mean disc height/space following fusion procedures and is maintained in the PLC preserved group during the one year follow up period.

In the PLC not preserved group slight reduction in mean disc height was observed at the final follow up, but there was no significant reduction to be met for the criteria of ASD. In a study done by Haichun liu comparing three surgical decompression techniques during 5- 7 year follow up period, it was observed that the mean disc height was significantly reduced in the group who underwent complete laminectomy with removal of PLC. 10

\section{Disc Angle}

In the PLC preserved group the median IV disc angle of the adjacent segment was $6(5,7)$ in the pre op, $7(6,8)$ in the immediate post op and $7(6,8)$ at 1 year follow up. In the PLC not preserved group the median IV disc angle was $6(5,7)$ at pre op, $7(6,7)$ at immediate post op and $7(6,8)$. There was no statistically significant difference between two groups in IV-disc angle pre-operative, post-operative and 1 year follow up. In study by Haichun liu comparing three surgical decompression techniques during 5- 7 year follow up period it was observed that the adjacent segment IV disc angle was significantly higher at final follow up in all the three groups than at the time of the preoperative assessment. And it was also noted that the disc angle in group which underwent complete laminectomy was significantly higher than in the other 2 groups which underwent PLC preservation in group 1 and semi laminectomy in group 2 respectively. ${ }^{10}$

\section{Total Lumbar Lordosis}

In the PLC preserved group the median total lumbar lordosis at pre op was $60.5(58,65.75)$, immediate post op was 62 $(58.25,64.75)$ and at 1 year follow up was $63(59,65)$.In the PLC not preserved group the median total lumbar lordosis was $63(56.25,66)$, immediate post op was $61(58,66)$ and at 1 year follow up was $62(59,66)$. There was no statistically significant difference between two groups in total lumbar lordosis preoperative, post-operative and 1 year follow up. In study by Haichun liu comparing three surgical decompression techniques during 5- 7 year follow up period it was observed that there was significant reduction in lumbar lordosis in the group who underwent complete laminectomy without preservation of PLC. ${ }^{10}$

\section{CONCLUSIONS}

Lumbar decompressive surgeries with both PLC preserving and non-preserving surgeries can provide significant relief of symptoms to the patient. PLC preserving surgeries provide better functional outcome during the 1 year follow up period. Similarly residual pain was also less in the PLC preserved group. Adjacent segment degeneration was not detected in both the groups during the one year follow up.

\section{Limitations}

The small sample size and limited period of follow up were possible limitations of the study. Minimal alterations in radiological parameters might have occurred by even slight variations in position of the patients from the prescribed stance. As disability was assessed based on self-answered questionnaire about symptoms, subjective variations could have arisen.

Data sharing statement provided by the authors is available with the full text of this article at jemds.com. 
Financial or other competing interests: None.

Disclosure forms provided by the authors are available with the full text of this article at jemds.com.

\section{REFERENCES}

[1] Haddadi K, Qazvini HRG. Outcome after surgery of lumbar spinal stenosis: a randomized comparison of bilateral laminotomy, trumpet laminectomy, and conventional laminectomy. Front Surg 2016;3:19.

[2] Verbiest H. A radicular syndrome from developmental narrowing of the lumbar vertebral canal. J Bone Joint Surg Br 1954;36-B(2):230-7.

[3] Wheeless CR. Wheeless' textbook of orthopaedics. C.R. Wheeless MD 1996.

[4] Deyo RA, Mirza SK, Martin BI, et al. Trends, major medical complications, and charges associated with surgery for lumbar spinal stenosis in older adults. JAMA 2010;303(13):1259-65.
[5] Spivak JM. Degenerative lumbar spinal stenosis. J Bone Joint Surg Am 1998;80(7):1053-66.

[6] Liu WJ, Hong SW, Liou DY, et al. Clinical outcomes following sublaminar-trimming laminoplasty for extensive lumbar canal stenosis. Eur Spine J 2014;23(1):80-6.

[7] Simotas AC. Nonoperative treatment for lumbar spinal stenosis. Clin Orthop Relat Res 2001;(384):153-61.

[8] Weinstein JN, Tosteson TD, Lurie JD, et al. Surgical versus nonoperative treatment for lumbar spinal stenosis fouryear results of the Spine Patient Outcomes Research Trial. Spine 2010;35(14):1329-38.

[9] Tuli SM, Kapoor V, Jain AK, et al. Spinaplasty following lumbar laminectomy for multilevel lumbar spinal stenosis to prevent iatrogenic instability. Indian J Orthop 2011;45(5):396-403.

[10] Liu H, Wu W, Li Y, et al. Protective effects of preserving the posterior complex on the development of adjacentsegment degeneration after lumbar fusion: clinical article. J Neurosurg Spine 2013;19(2):201-6. 